\title{
Association between the 5-HTTLPR Genotype and Childhood Characteristics in Mood Disorders
}

\author{
Tae Kyung Eun ${ }^{1}$, Seong Hoon Jeong ${ }^{2,3}$, Kyu Young Lee ${ }^{1,2}$, Se Hyun Kim ${ }^{4}$, Yong Min Ahn ${ }^{5,6,7}$, Yang Weon Bang ${ }^{8}$, \\ Eun-Jeong Joo ${ }^{1,2}$ \\ 'Department of Psychiatry, Eulji General Hospital, Seoul, 'Department of Neuropsychiatry, Eulji University School of Medicine, Daejeon, \\ ${ }^{3}$ Department of Psychiatry, Eulji University Hospital, Daejeon, ${ }^{4}$ Department of Neuropsychiatry, Dongguk University Ilsan Hospital, Dongguk \\ University School of Medicine, Goyang, ${ }^{5}$ Departments of Psychiatry and Behavioral Science, Seoul National University College of Medicine, \\ Seoul, ${ }^{6}$ Department of Neuropsychiatry and ${ }^{7}$ Biomedical Research Institute, Seoul National University Hospital, Seoul, ${ }^{8}$ Department of \\ Psychiatry, Keyo Hospital, Uiwang, Korea
}

\begin{abstract}
Objective: The features of childhood attention deficit hyperactivity disorder (ADHD) are significantly associated with adult mood disorders. Some genetic factors may be common to both ADHD and mood disorders underlie the association between these two phenotypes. The present study aimed to determine whether a genetic role may be played by the serotonin transporter-linked polymorphic region (5-HTTLPR) in the childhood ADHD features of adult patients with mood disorders.

Methods: The present study included 232 patients with major depressive disorder (MDD), 154 patients with bipolar disorder (BPD), and 1,288 normal controls. Childhood ADHD features were assessed with the Korean version of the Wender Utah Rating Scale (WURS-K). The total score and the scores of three factors (impulsivity, inattention, and mood instability) from the WURS-K were analyzed to determine whether they were associated with the 5-HTTLPR genotype.

Results: In the BPD type II group, the 5-HTTLPR genotype was significantly associated with the total score $(p=0.029)$ and the impulsivity factor $(p=0.004)$ on the WURS $-\mathrm{K}$. However, the inattention and mood instability factors were not associated with the 5-HTTLPR genotype. BPD type I, MDD and normal control groups did not exhibit any significant associations between the WURS-K scores and the 5-HTTLPR genotype.

Conclusion: The findings suggest that the 5-HTTLPR genotype may play a role in the impulsivity component of childhood ADHD in patients with BPD type II. Because of a small sample size and a single candidate gene, further studies investigating other candidate genes using a larger sample are warranted to determine any common genetic links.
\end{abstract}

KEY WORDS: 5-HTTLPR; Attention deficit hyperactivity disorder; Childhood; Impulsivity; Mood disorders; Wender Utah Rating Scale.

\section{INTRODUCTION}

In many respects, there are significant overlaps between mood disorders and attention deficit hyperactivity disorder (ADHD). First, ADHD is one of the most frequent comorbid psychiatric conditions observed among patients with bipolar disorder (BPD) during childhood. For example, in the United States, ADHD is frequently diagnosed in children with BPD, and BPD is often comorbid in children with ADHD. ${ }^{1,2)}$ Second, both of these dis-

\footnotetext{
Received: August 4, 2015 / Revised: October 11, 2015

Accepted: November 17, 2015

Address for correspondence: Eun-Jeong Joo, MD, PhD

Department of Psychiatry, Eulji General Hospital, 68 Hangeulbiseok-ro, Nowon-gu, Seoul 01830, Korea

Tel: +82-2-970-8611, Fax: +82-2-949-2356

E-mail: jej1303@gmail.com
}

orders are more frequently identified in the relatives of patients with the other disorder compared with the normal population. One meta-analysis found that ADHD is more common in the relatives of patients with BPD than in normal controls and that BPD is more common in the relatives of patients with ADHD than in normal controls. ${ }^{3)}$ Third, in clinical terms, the features of ADHD are often so confused with those of BPD, especially during childhood, that some cases have ambiguous diagnoses. Fourth, it has been suggested that the features of childhood ADHD are related to adult mood disorders. The impulsivity and inattention associated with childhood ADHD as measured by the Wender Utah Rating Scale (WURS) are more significantly related to BPD type II (BPD II) than to BPD type I (BPD I). Additionally, our research group has shown that the mood instability and anxiety associated

(a) This is an Open-Access article distributed under the terms of the Creative Commons Attribution Non-Commercial License (http://creativecommons.org/licenses/by-nc/4.0) which permits unrestricted non-commercial use, distribution, and reproduction in any medium, provided the original work is properly cited. 
with childhood ADHD are significantly related to major depressive disorder (MDD) in adulthood. ${ }^{4)}$ Taken together, these findings suggest that ADHD and mood disorders may share common genetic susceptibilities. Although there are many possible genetic candidates, the serotonin transporter gene is one of the most promising options because serotonergic neural transmission is well known to be important in mood, attention, and impulse control.

The serotonin transporter-linked polymorphic region (5-HTTLPR) for SLC6A4 is a 44-bp insertion/deletion variable-number tandem repeat polymorphism located upstream of the transcription initiation site. This genetic region has two common variations: a long allele (l allele, 16 repeats) and a short allele (s allele, 14 repeats). Because the job of the serotonin transporter is to reuptake serotonin from the neuronal synapse, its function likely plays a major role in determining the activity of serotonin in the synapse. The s allele has a lower transcriptional efficiency than the 1 allele has ${ }^{5,6)}$ and typically exhibits a greater degree of vulnerability to social stressors. ${ }^{7,8}$ However, there is still controversy regarding the association of 5HTTLPR with depression. The recent study investigating this link was a meta-analysis of 54 studies, which found that the $\mathrm{s}$ allele was associated with an increased risk of depression under conditions of stress. ${ }^{9}$

Thus, the present study evaluated the possible genetic contribution of 5-HTTLPR to the features of childhood ADHD in adult patients with different types of mood disorders including BPD I, BPD II, MDD single episode, and MDD recurrent. Childhood ADHD features were measured using the Korean version of the WURS (WURS-K), and factor analyses were also performed. Association analyses were conducted to determine the relationships of the factors of the WURS-K with the 5-HTTLPR genotype.

\section{METHODS}

\section{Subjects}

Our research group has previously reported that patients with mood disorders and healthy adults have significantly different factor scores on the WURS. ${ }^{4}$ The present study utilized the same pool of normal controls and patients with mood disorders as participated our previous study but also included additional subjects because more patients were continuously recruited after the completion of the previous reports. All patients were recruited from Eulji General Hospital (Seoul, Korea) and Seoul National University Hospital (Seoul, Korea) and were diagnosed based on the diagnostic criteria of the Diagnostic and Statistical Manual of Mental Disorders, 4th edition (DSM-IV). The patients were individually interviewed by research nurses using the Korean version of the MiniInternational Neuropsychiatric Interview (MINI), and consensus diagnostic meetings between two psychiatrists, including the psychiatrist in charge of the psychiatric treatment of each patient, were conducted to determine the final diagnosis of each subject.

Subjects were excluded from the present analyses if they had a history of any kind of organic brain abnormality, substance dependence, drug abuse, or any other physical condition that could manifest as a psychiatric disorder. The normal control subjects were recruited from among college students, nurses, and fire and public protection officers. Each control subject completed a brief psychiatric interview performed by a psychiatric research nurse to evaluate current and past psychiatric illnesses. Subjects with a lifetime history of major psychiatric illness and/or brain trauma were excluded from the control group. All patients and control subjects were ethnically Korean. The final analyses of the present study included 232 patients with MDD (88 patients with MDD single episode and 144 patients with MDD recurrent), 154 patients with BPD (117 patients with BPD I and 37 patients with BPD II), and 1,288 normal controls. All subjects who participated in this study signed a written informed consent form, and the study protocol was approved by the ethics committee of Eulji General Hospital (Eulji 12-69).

\section{Measurement of Childhood ADHD Features}

The childhood ADHD features of the subjects were measured using the WURS-K. The WURS consists of 61 items and was developed to retrospectively assess adults to determine the severity of their ADHD symptoms during childhood. ${ }^{10)}$ The short form of the WURS includes 25 of the original items. The WURS-K was developed from the short form of the WURS and was standardized using normal Korean female adults. ${ }^{11-14)}$

\section{Genotyping}

DNA was extracted from blood samples using a DNA isolation kit (Roche, Mannheim, Germany), and the 5-HTTLPR polymorphism was genotyped by synthesizing the primers for 5-HTTLPR with the sequences for stpr5 (5'-GGCGTTGCCGCTCTGAATGC-3') and stpr3 (5'-GAGGGACTGAGCTGGACAACCAC-3'). A $10 \mu 1$ aliquot with $50 \mathrm{ng} / \mu 1$ of DNA, $2 \mu 1$ of $20 \mathrm{mM}$ dNTP mix (Roche), $0.5 \mu 1$ of each $20 \mathrm{pM}$ primer, $1.5 \mu 1$ of $10 \times$ buffer, $1.5 \mathrm{U}$ of Taq polymerase (Roche), and $9.2 \mu 1$ of dis- 
tilled water was mixed to create a $15 \mu 1$ polymerase chain reaction (PCR) reaction volume. The $\mathrm{PCR}$ procedure was carried out as follows: 5 minutes at $94^{\circ} \mathrm{C}$ to denature the DNA sequence, 35 cycles at $94^{\circ} \mathrm{C}$ for 30 seconds, $64^{\circ} \mathrm{C}$ for 30 seconds, and $72^{\circ} \mathrm{C}$ for 1 minute, and then 7 minutes for amplification at $72^{\circ} \mathrm{C}$. The PCR products were examined by electrophoresis for 30 minutes on a 3\% agarose gel stained with ethidium bromide. The DNA sequencing of the PCR products for several subjects was performed to confirm the 5-HTTLPR genotype.

\section{Statistical Analysis}

For the factor analysis, a principal component analysis was conducted. The Kaiser-Meyer-Olkin measure of sampling adequacy (0.95) and Barlett's test of sphericity $(p$ $<0.001$ ) showed that this sample was appropriate for the factor analysis. Because previous studies have shown that the WURS-K has a consistent three-factor structure, ${ }^{12-14)}$ the factor analysis was performed under conditions in which only three factors could be extracted. These three factors were correlated with one another, and a promax rotation was performed to maximize the loading of each variable on one of the extracted factors and to minimize the loading on all other factors; the rotation converged after nine iterations. Subsequently, an analysis of variance (ANOVA) was performed to compare the scores of the five diagnostic groups (BPD I, BPD II, MDD single, MDD recurrent, and control), and then the total and factor scores on the WURS-K were compared among the 5HTTLPR genotypes (ss, sl, 1l) within each group using ANOVA. A $p$ value $<0.05$ was considered to indicate statistical significance. Additionally, a genotype association analysis of the five diagnostic groups was performed using a chi-square test. Statistical Package for the Social Science (SPSS) ver. 12.0 software (SPSS Inc., Chicago, IL, USA) was used for all analyses.

\section{RESULTS}

\section{Demographic Characteristics}

The gender distribution of the sample population in the present study was not even because more female subjects were available during the collection of the sample; the number of females subjects $(\mathrm{n}=1,093)$ was almost double the number of male subjects $(\mathrm{n}=581)$. However, the proportion of female subjects in each of the diagnostic groups was similar. The mean ages for the MDD, BPD, and normal control groups were $52.81 \pm 14.20$ years, $37.69 \pm 12.97$ years, and $25.07 \pm 6.05$ years, respectively. Additional detailed information regarding the number of subjects and the mean age for each group is provided in Table 1.

\section{Factor Analysis of the WURS-K}

The loading patterns of the three factors were matched with the terms impulsivity, inattention, and mood instability, as previously described in studies from our research group and others. ${ }^{4,14,15}$ The factors explained $50.44 \%$ of the total variance, including $41.80 \%$ of the variance for the impulsivity factor, $8.06 \%$ of the variance for the inattention factor, and $6.29 \%$ of the variance for the mood instability factor. The three factors were correlated with one another; the correlation coefficients for impulsivity and inattention, impulsivity and mood instability, and inattention and mood instability were $0.49,0.58$, and 0.49 , respectively (Table 2 ).

\section{WURS-K Total and Factor Scores}

The WURS-K total scores for the MDD, BPD, and normal control groups were $27.72 \pm 20.96,24.08 \pm 19.21$, and $19.37 \pm 14.77$, respectively. Additional detailed information regarding gender is provided in Table 1 . As expected, based on our previous findings, ${ }^{4,14)}$ there was a highly significant difference in the total and factor scores among the

Table 1. Number of subjects, age, and WURS-K total score for each diagnostic group

\begin{tabular}{|c|c|c|c|c|c|c|c|c|c|}
\hline \multirow[b]{2}{*}{ Diagnosis } & \multicolumn{3}{|c|}{ Total } & \multicolumn{3}{|c|}{ Male } & \multicolumn{3}{|c|}{ Female } \\
\hline & $\begin{array}{l}\text { Subject } \\
\text { (n) }\end{array}$ & $\begin{array}{l}\text { Age } \\
(y r)\end{array}$ & $\begin{array}{l}\text { WURS-K } \\
\text { total score }\end{array}$ & $\begin{array}{l}\text { Subject } \\
\text { (n) }\end{array}$ & $\begin{array}{l}\text { Age } \\
(y r)\end{array}$ & $\begin{array}{l}\text { WURS-K } \\
\text { total score }\end{array}$ & $\begin{array}{l}\text { Subject } \\
\text { (n) }\end{array}$ & $\begin{array}{l}\text { Age } \\
(y r)\end{array}$ & $\begin{array}{l}\text { WURS-K } \\
\text { total score }\end{array}$ \\
\hline Control & 1,288 & $25.07 \pm 6.05$ & $19.37 \pm 14.77$ & 475 & $27.39 \pm 8.34$ & $19.47 \pm 15.66$ & 813 & $23.71 \pm 3.53$ & $19.31 \pm 14.23$ \\
\hline $\mathrm{MDD}$ & 232 & $52.81 \pm 14.20$ & $27.72 \pm 20.96$ & 51 & $51.12 \pm 18.45$ & $33.14 \pm 23.99$ & 181 & $53.29 \pm 12.77$ & $26.19 \pm 19.82$ \\
\hline MDD, single & 88 & $50.22 \pm 16.17$ & $26.36 \pm 21.69$ & 25 & $51.12 \pm 17.95$ & $31.92 \pm 24.44$ & 63 & $49.86 \pm 15.55$ & $24.16 \pm 20.29$ \\
\hline MDD, recurrent & 144 & $54.40 \pm 12.64$ & $28.55 \pm 20.53$ & 26 & $51.12 \pm 19.28$ & $34.31 \pm 23.99$ & 118 & $55.12 \pm 10.63$ & $27.28 \pm 19.57$ \\
\hline $\mathrm{BPD}$ & 154 & $37.69 \pm 12.97$ & $24.08 \pm 19.21$ & 55 & $37.80 \pm 13.42$ & $26.89 \pm 19.45$ & 99 & $37.63 \pm 12.79$ & $22.52 \pm 18.99$ \\
\hline BPD, type I & 117 & $38.62 \pm 12.95$ & $22.49 \pm 18.87$ & 47 & $37.74 \pm 13.24$ & $25.62 \pm 18.43$ & 70 & $39.21 \pm 12.81$ & $20.39 \pm 19.00$ \\
\hline BPD, type ॥ & 37 & $34.73 \pm 12.79$ & $29.11 \pm 19.65$ & 8 & $38.13 \pm 15.40$ & $34.38 \pm 24.69$ & 29 & $33.79 \pm 12.11$ & $27.66 \pm 18.27$ \\
\hline
\end{tabular}

Values are presented as number only or mean \pm standard deviation.

WURS-K, Korean version of the Wender Utah Rating Scale; MDD, major depressive disorder; BPD, bipolar disorder. 
Table 2. WURS items and three factor structure

\begin{tabular}{|c|c|c|c|}
\hline \multirow{2}{*}{ Variable } & Factor 1 & Factor 2 & Factor 3 \\
\hline & Impulsivity & Inattention & Mood Instability \\
\hline \multicolumn{4}{|l|}{ WURS Items } \\
\hline Temper outbursts, tantrums & 0.79 & -0.12 & 0.09 \\
\hline Stubborn, strong willed & 0.76 & -0.18 & -0.09 \\
\hline Disobedient, rebellious, sassy & 0.75 & -0.03 & 0.02 \\
\hline Acting without thinking, impulsive & 0.75 & 0.27 & -0.21 \\
\hline Trouble with authorities \& school, visits to principal's office & 0.63 & 0.14 & -0.21 \\
\hline Irritable & 0.59 & -0.14 & 0.41 \\
\hline Hot or short tempered, low boiling point & 0.59 & -0.16 & 0.39 \\
\hline Tendency to be or act irrational & 0.58 & 0.28 & -0.02 \\
\hline Trouble seeing things from someone else's point of view & 0.57 & 0.29 & -0.09 \\
\hline Angry & 0.54 & -0.16 & 0.50 \\
\hline Moody, ups and downs & 0.50 & -0.11 & 0.43 \\
\hline Trouble with stick-to-it-tiveness & 0.38 & 0.36 & -0.01 \\
\hline Overall a poor student, slow learner & -0.05 & 0.81 & -0.01 \\
\hline Trouble with mathematics or numbers & -0.13 & 0.74 & 0.05 \\
\hline Not achieving up to potential & -0.16 & 0.71 & 0.21 \\
\hline Unpopular with other children & 0.06 & 0.52 & 0.11 \\
\hline Tendency to be immature & 0.40 & 0.52 & -0.08 \\
\hline Losing control of myself & 0.44 & 0.48 & -0.02 \\
\hline Concentration problems, easily distracted & 0.14 & 0.28 & 0.10 \\
\hline Inattentive, daydreaming & 0.09 & 0.37 & 0.36 \\
\hline Anxious, worrying & -0.18 & 0.10 & 0.89 \\
\hline Sad or blue, depressed, unhappy & 0.04 & 0.01 & 0.80 \\
\hline Nervous, fidgety & -0.03 & 0.07 & 0.80 \\
\hline Low opinion of myself & -0.14 & 0.31 & 0.64 \\
\hline Guilty feeling, regretful & -0.10 & 0.41 & 0.58 \\
\hline Initial eigen values & 10.45 & 2.02 & 1.57 \\
\hline Eigen values after rotation & 8.46 & 6.91 & 7.52 \\
\hline$\%$ of variance & 41.80 & 8.06 & 6.29 \\
\hline \multicolumn{4}{|l|}{ Component correlation } \\
\hline Impulsivity & 1.00 & 0.49 & 0.58 \\
\hline Inattention & 0.49 & 1.00 & 0.49 \\
\hline Mood instability & 0.58 & 0.49 & 1.00 \\
\hline
\end{tabular}

WURS, Wender Utah Rating Scale.

diagnostic groups, $\mathrm{F}=16.079, p<0.001$ for the total score, $\mathrm{F}=2.966, p=0.019$ for the impulsivity factor, $\mathrm{F}=23.846, p$ $<0.001$ for the inattention factor, and $\mathrm{F}=20.439, p$ $<0.001$ for the mood instability factor. The differences among the diagnostic groups are illustrated in Figure 1.

\section{Associations of the Factor Scores with the 5-HTTLPR Genotype}

In the BPD II group, the 5-HTTLPR genotype was significantly associated with the total score $(p=0.029)$ and the impulsivity factor $(p=0.004)$ on the WURS-K. However, neither the inattention factor nor the mood instability factor was associated with the 5-HTTLPR genotype. In the BPD I, MDD, and normal control groups, no associations between the WURS scores and the 5-HTTLPR genotype were found. Table 3 summarizes the results of the association analyses.

\section{Associations of the Mood Disorders with the 5-HTTLPR Genotype}

A chi-square test comparing the BPD, MDD, and normal control groups was performed to investigate whether there was an association between the 5-HTTLPR genotype and the diagnosis of a mood disorder rather than any quantitative subphenotype. No such association was found, and additional analyses according to gender also found no associations (Table 4).

\section{DISCUSSION}

The serotonergic system is thought to be the most important underlying component of mood disorders, and a number of studies have investigated the role of this neurotransmitter in patients with MDD and BPD. ${ }^{16-18)}$ In contrast, few studies have investigated the role of serotonergic genes in ADHD. Animal studies have suggested that 
A

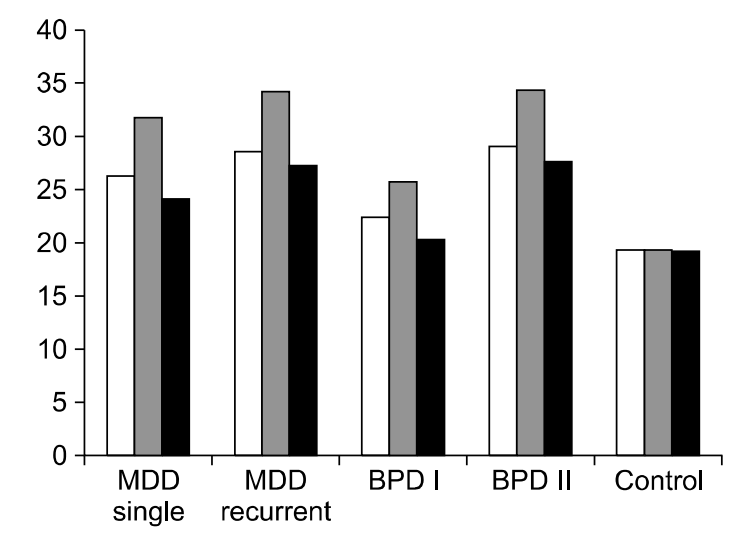

C

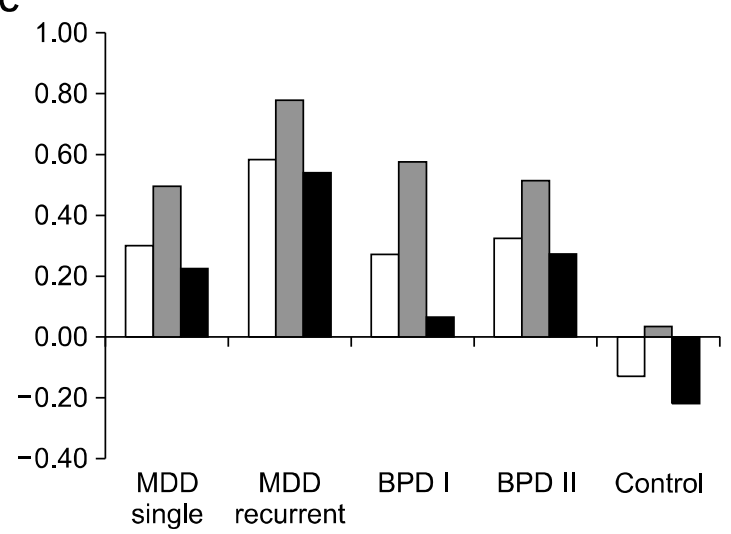

B

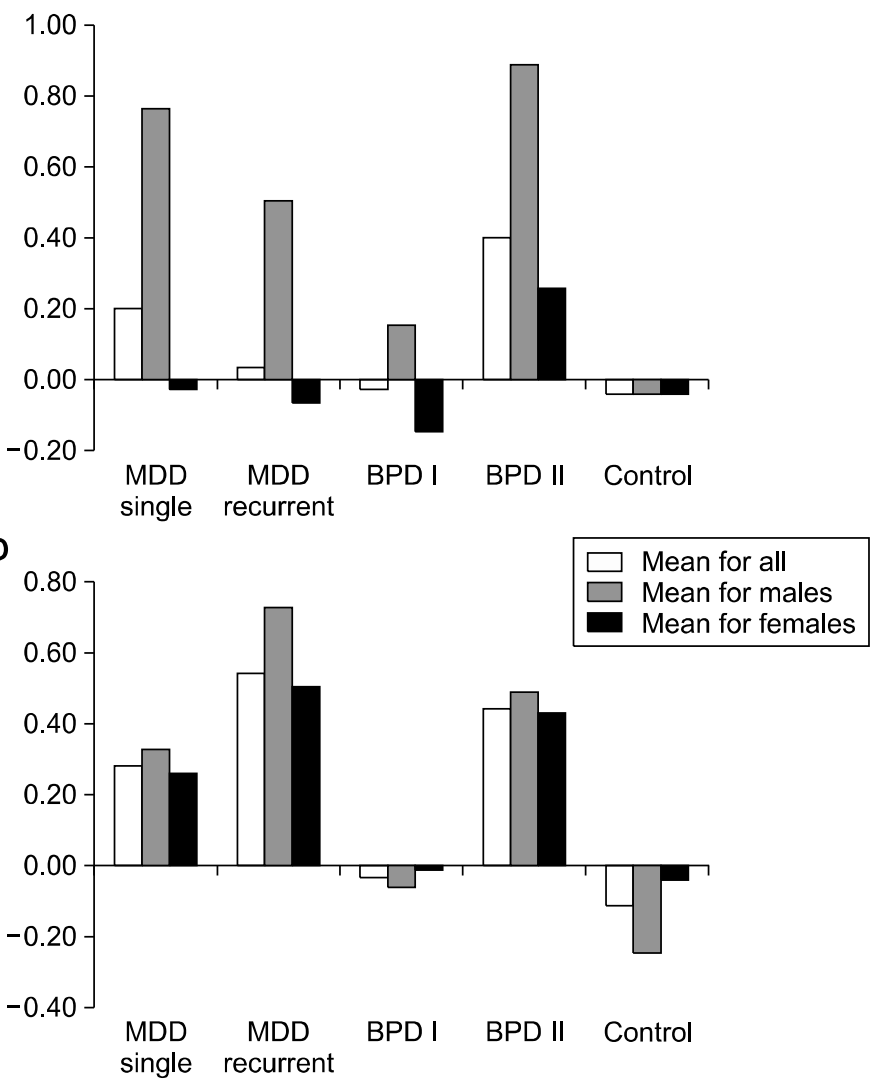

Fig. 1. Comparisons of the Korean version of the Wender Utah Rating Scale (WURS-K) scores among the five diagnostic groups. (A) Total score, (B) impulsivity factor score, (C) inattention factor score, and (D) mood instability factor score on the WURS-K. MDD, major depressive disorder; BPD, bipolar disorder.

Table 3. Associations between the WURS-K scores and the 5-HTTLPR genotype

\begin{tabular}{|c|c|c|c|c|c|c|c|c|}
\hline \multirow{2}{*}{ Group } & \multicolumn{2}{|c|}{ WURS total } & \multicolumn{2}{|c|}{ Fl, impulsivity } & \multicolumn{2}{|c|}{ F2, Inattention } & \multicolumn{2}{|c|}{ F3, Mood Instability } \\
\hline & $\mathrm{F}$ & $p$ value & $\mathrm{F}$ & $p$ value & $\mathrm{F}$ & $p$ value & $\mathrm{F}$ & $p$ value \\
\hline Control & 1.11 & 0.33 & 0.69 & 0.51 & 1.47 & 0.23 & 0.40 & 0.67 \\
\hline MDD & 0.25 & 0.78 & 0.40 & 0.70 & 0.05 & 0.96 & 0.24 & 0.79 \\
\hline MDD, single & 0.64 & 0.53 & 0.65 & 0.53 & 0.14 & 0.87 & 1.54 & 0.22 \\
\hline MDD, recurrent & 0.49 & 0.62 & 1.76 & 0.18 & 0.14 & 0.87 & 0.06 & 0.95 \\
\hline $\mathrm{BPD}$ & 0.53 & 0.59 & 0.05 & 0.95 & 1.65 & 0.20 & 0.36 & 0.70 \\
\hline BPD, type I & 1.56 & 0.22 & 1.35 & 0.26 & 1.55 & 0.22 & 0.76 & 0.47 \\
\hline BPD, type ॥ & 3.94 & $0.03^{*}$ & 6.47 & $0.00^{*}$ & 2.70 & 0.08 & 0.79 & 0.46 \\
\hline
\end{tabular}

*Statistically significant $(p<0.05)$

WURS-K, Korean version of the Wender Utah Rating Scale; 5-HTTLPR, serotonin transporter-linked polymorphic region; F1, factor 1; F2, factor 2; F3, factor 3; MDD, major depressive disorder; BPD, bipolar disorder.

serotonergic pathways are a significant contributor to the development of ADHD, ${ }^{19,20)}$ and human studies have shown that there are associations between self-blame and ADHD symptoms in patients with the high and low serotonin activity genotypes. ${ }^{21)}$ Furthermore, 5-HTTLPR has pleiotropic effects on the childhood adversity associated with ADHD as well as violent behavior. ${ }^{22)}$
The comorbidity of mood disorders and ADHD is not rare in clinics, and in fact, more severe mood disorders are commonly associated with comorbid ADHD. ${ }^{23)}$ Unfavorable side effects from being medicated with a mood stabilizer have also been reported. ${ }^{24)}$ Similar to ADHD and BPD, the comorbidity of MDD with ADHD is associated with more severe clinical manifestations. Comorbid patients have 
Table 4. Genotype distribution of 5-HTTLPR for each diagnostic group of mood disorders

\begin{tabular}{|c|c|c|c|c|c|c|c|c|c|}
\hline \multirow{2}{*}{ Group } & \multicolumn{3}{|c|}{ Total } & \multicolumn{3}{|c|}{ Male } & \multicolumn{3}{|c|}{ Female } \\
\hline & ss & sl & $\|$ & ss & sl & $\|$ & ss & sl & $\|$ \\
\hline Control & 814 & 386 & 88 & 327 & 117 & 31 & 487 & 269 & 57 \\
\hline MDD, single & 58 & 28 & 2 & 17 & 8 & 0 & 41 & 20 & 2 \\
\hline $\begin{array}{l}\text { MDD, } \\
\text { recurrent }\end{array}$ & 95 & 35 & 14 & 14 & 8 & 4 & 81 & 27 & 10 \\
\hline BPD, type I & 75 & 36 & 6 & 32 & 14 & 1 & 43 & 22 & 5 \\
\hline BPD, type ॥ & 26 & 10 & 1 & 6 & 2 & 0 & 20 & 8 & 1 \\
\hline$F$ & & 8.127 & & & 8.961 & & & 7.483 & \\
\hline$p$ value & & 0.421 & & & 0.346 & & & 0.486 & \\
\hline
\end{tabular}

5-HTTLPR, serotonin transporter-linked polymorphic region; s, short allele of 5-HTTLPR; I, long allele of 5-HTTLPR; MDD, major depressive disorder; BPD, bipolar disorder.

more frequent recurrence of $\mathrm{MDD},{ }^{25)}$ an earlier age of onset, longer duration of depressive illness, and higher rates of suicidality and hospitalization than do MDD patients without ADHD. ${ }^{26)}$ Taken together, these studies indicate that there are common genetic vulnerabilities underlying ADHD and mood disorders, but the specific genetic factors associated with comorbid ADHD and mood disorders are different from those associated with mood disorder patients without ADHD.

In the present study, the frequencies of the 1 allele in the control group and among all patients were $21.8 \%$ and $19.0 \%$, respectively, and the frequencies of the 11 genotype in the control group and for all patients were $6.8 \%$ and $5.7 \%$, respectively. These profiles are consistent with previous studies of Asian populations, including Korean, ${ }^{27-29)}$ but are very different from studies of Caucasian populations. In Caucasians, the frequencies of the 11 genotype and 1 allele were $33 \%$ and $55 \%$, respectively. ${ }^{30)}$ In the present study, there was a significant association between childhood impulsivity and the 5-HTTLPR genotype, but only in patients with BPD II. More specifically, the 11 genotype was associated with a greater degree of childhood impulsivity in BPD II patients; moreover, there were dose (number of 1 allele)-dependent relationships among the 11 , ls, and ss genotypes along a spectrum from more impulsive to less impulsive. This particular finding does not agree with those of most previous studies that have investigated the association of the $\mathrm{s}$ allele with a particular psychopathology. For example, the ss genotype of 5HTTLPR was shown to have a strong association with conduct disorder, ${ }^{31)}$ and the s allele was significantly related with violent suicidal attempts in schizophrenia patients. $^{32)}$ In contrast, it has also been reported that 5-HTTLPR is not associated with the response to methylphenidate treatment ${ }^{33)}$ or aggressive behavior in ADHD patients. ${ }^{34)}$ For mood disorder, since a lot of studies done on the relationship between 5-HTTLPR and depression worldwide, meta-analytic studies investigating whether $\mathrm{s}$ or 1 allele is associated with depression have been conducted. In the meta-analysis done by Karg et al. ${ }^{9)}$ the main finding was that s allele of the 5-HTTLPR was associated with increased risk of MDD following stressors. However, contrary to the main finding, 15 out of the 54 studies reported no association between the s allele, stress and depression. Furthermore, six studies reported that 1 allele was associated with depression after significant stress. In spite of the robust overall evidence of association between s allele of the 5-HTTLPR, environmental stress and depression, it should not be ignored this association is not universal, i.e., there are studies found the association between 1 allele and depression under the stress. ${ }^{17)}$ In general, the role of 5-HTTLPR in the manifestation of ADHD and depression is inconclusive, and further study is required to elucidate this issue because the biological meaning of this genotypic association remains unclear.

The comparisons of the WURS-K scores among the different diagnostic groups are illustrated in Figure 1. BPD II patients had the highest total score on the WURS-K. Our research group has previously demonstrated that the impulsivity and inattention factors associated with childhood ADHD are more significantly related to BPD II than to BPD I. ${ }^{4)}$ In the present study, the MDD group was subdivided into MDD recurrent and MDD single episode groups, and the MDD recurrent group exhibited the second highest WURS total and factor scores of all subjects. Thus, the BPD II group was more similar to the MDD recurrent group than the BPD I group was. Furthermore, although the MDD recurrent group was found to be similar to the BPD II group as a phenotype based on the WURS-K scores, this MDD group differed from the BPD II group in that there was no association with 5-HTTLPR. Therefore, the MDD recurrent group would be more homogenous as a diagnostic entity than the MDD single group would. Furthermore, if the MDD group were not differentially categorized as MDD recurrent and MDD single, it is highly possible that there would be a phenocopy representing multiple origins and with considerable heterogeneity of genetic etiologies. Therefore, MDD recurrent patients should be studied independently of MDD single patients. In terms of childhood characteristics, the close relationship between MDD recurrent and BPD II in the present study suggests that these patients share a common developmental trajectory, but further investigation is required to elucidate this issue. 
BPD II is considered different from BPD I in many clinical aspects. BPD II patients are more likely to be female and to have an earlier age of onset, ${ }^{35)}$ and social and simple phobias are over-represented in BPD II patients. ${ }^{36}$ In terms of social function, BPD II patients exhibit higher rates of interpersonal conflicts, marital instability, and family breakdown. ${ }^{37)}$ In terms of temperament, elevated irritability, anxious worrying, self-criticism, interpersonal sensitivity, and lower social avoidance are more frequently observed in BPD II patients, ${ }^{38)}$ but the episodes are briefer and manifest in the same manner during euthymic periods. However, no published studies have investigated the developmental differences between patients with BPD I and patients with BPD II. The findings of the present study further support the differences between BPD I and BPD II regarding the childhood characteristics of patients and their association with 5-HTTLPR.

There are several limitations to the present study. First, the sample size of the BPD II patients was not sufficient to provide appropriate statistical significance. Second, 5HTTLPR is only one polymorphic site of the serotonin transporter gene, and cannot, in and of itself, represent the full association between the gene and a specific 5HTTLPR phenotype. However, the 5-HTTLPR polymorphism is a functional and very well-known candidate gene underlying a number of psychiatric disorders. Finally, although the present study analyzed the total score on the WURS-K, the data were also assessed using factor analyses and then analyzed separately according to the diagnostic groups. Thus, there is an issue regarding multiple comparisons, and the present findings should be interpreted cautiously due to the level of significance used.

In conclusion, the present findings suggest that the 5-HTTLPR genotype may play a role in the impulsivity expressed during childhood by adult BPD II patients. This relationship was not present for the other mood disorders assessed. Considering the sample size and level of significance in the present study, the genetic influence of 5-HTTLPR was not strong on the childhood ADHD features of patients with adult mood disorders. Thus, there are likely other genes that contribute as mediators between the features of childhood ADHD and adult mood disorders. Further studies on other candidate genes such as $5 H T 2 A$, $D A T 1$, and DRD4 are warranted to fully understand the possible common genetic relationships between mood disorders and ADHD. Additionally, larger sample sizes, particularly for BPD II patients, are necessary to support the present findings.

\section{Acknowledgments}

This study was supported by Eulji University in 2012 .

\section{REFERENCES}

1. Althoff RR, Faraone SV, Rettew DC, Morley CP, Hudziak JJ. Family, twin, adoption, and molecular genetic studies of juvenile bipolar disorder. Bipolar Disord 2005;7:598-609.

2. Singh MK, DelBello MP, Kowatch RA, Strakowski SM. Co-occurrence of bipolar and attention-deficit hyperactivity disorders in children. Bipolar Disord 2006;8:710-720.

3. Faraone SV, Biederman J, Mennin D, Wozniak J, Spencer T. Attention-deficit hyperactivity disorder with bipolar disorder: a familial subtype? J Am Acad Child Adolesc Psychiatry 1997;36:1378-1387; discussion 1387-90.

4. Joo EJ, Lee KY, Choi KS, Kim SH, Song JY, Bang YW, et al. Childhood attention deficit hyperactivity disorder features in adult mood disorders. Compr Psychiatry 2012;53:217-223.

5. Heils A, Teufel A, Petri S, Stöber G, Riederer P, Bengel D, et al. Allelic variation of human serotonin transporter gene expression. J Neurochem 1996;66:2621-2624.

6. Heils A, Teufel A, Petri S, Seemann M, Bengel D, Balling $\mathrm{U}$, et al. Functional promoter and polyadenylation site mapping of the human serotonin (5-HT) transporter gene. J Neural Transm Gen Sect 1995;102:247-254.

7. Caspi A, Sugden K, Moffitt TE, Taylor A, Craig IW, Harrington $\mathrm{H}$, et al. Influence of life stress on depression: moderation by a polymorphism in the 5-HTT gene. Science 2003;301:386-389.

8. Grabe HJ, Lange M, Wolff B, Völzke H, Lucht M, Freyberger HJ, et al. Mental and physical distress is modulated by a polymorphism in the 5-HT transporter gene interacting with social stressors and chronic disease burden. Mol Psychiatry 2005;10:220-224.

9. Karg K, Burmeister M, Shedden K, Sen S. The serotonin transporter promoter variant (5-HTTLPR), stress, and depression meta-analysis revisited: evidence of genetic moderation. Arch Gen Psychiatry 2011;68:444-454.

10. Ward MF, Wender PH, Reimherr FW. The Wender Utah Rating Scale: an aid in the retrospective diagnosis of childhood attention deficit hyperactivity disorder. Am J Psychiatry 1993;150:885-890.

11. Koo YJ, Choi KS, Bang YW, Kim OS, Song HJ, Joo EJ. Factor structure of Wender Utah Rating Scale (Korean) in normal female adults. J Soc Korean Women Psychiatr 2009; 7:63-67.

12. McCann BS, Scheele L, Ward N, Roy-Byrne P. Discriminant validity of the Wender Utah Rating Scale for attention-deficit/hyperactivity disorder in adults. $J$ Neuropsychiatry Clin Neurosci 2000;12:240-245.

13. Fossati A, Di Ceglie A, Acquarini E, Donati D, Donini M, Novella $\mathrm{L}$, et al. The retrospective assessment of childhood attention deficit hyperactivity disorder in adults: reliability and validity of the Italian version of the Wender Utah Rating Scale. Compr Psychiatry 2001;42:326-336.

14. Joo EJ, Greenwood TA, Schork N, McKinney RA, Sadovnick AD, Remick RA, et al. Suggestive evidence for linkage of $A D H D$ features in bipolar disorder to chromosome 10p14. Am J Med Genet B Neuropsychiatr Genet 2010;153B:260-268

15. Jeong $\mathrm{SH}$, Yu JC, Lee $\mathrm{CH}$, Choi KS, Choi JE, Kim SH, et al. Human CLOCK gene-associated attention deficit 
hyperactivity disorder-related features in healthy adults: quantitative association study using Wender Utah Rating Scale. Eur Arch Psychiatry Clin Neurosci 2014;264:71-81.

16. Olivier B. Serotonin: a never-ending story. Eur J Pharmacol 2015;753:2-18.

17. Sharpley CF, Palanisamy SK, Glyde NS, Dillingham PW, Agnew LL. An update on the interaction between the serotonin transporter promoter variant (5-HTTLPR), stress and depression, plus an exploration of non-confirming findings. Behav Brain Res 2014;273:89-105.

18. Kishi T, Yoshimura R, Fukuo Y, Okochi T, Matsunaga S, Umene-Nakano $\mathrm{W}$, et al. The serotonin 1 A receptor gene confer susceptibility to mood disorders: results from an extended meta-analysis of patients with major depression and bipolar disorder. Eur Arch Psychiatry Clin Neurosci 2013;263:105-118.

19. Giros B, Jaber M, Jones SR, Wightman RM, Caron MG. Hyperlocomotion and indifference to cocaine and amphetamine in mice lacking the dopamine transporter. Nature 1996;379:606-612.

20. Tanaka K, Shintani N, Hashimoto H, Kawagishi N, Ago Y, Matsuda T, et al. Psychostimulant-induced attenuation of hyperactivity and prepulse inhibition deficits in Adcyap1deficient mice. J Neurosci 2006;26:5091-5097.

21. Nikolas M, Friderici K, Waldman I, Jernigan K, Nigg JT. Gene $x$ environment interactions for ADHD: synergistic effect of 5HTTLPR genotype and youth appraisals of inter-parental conflict. Behav Brain Funct 2010;6:23.

22. Retz W, Rösler M. The relation of $A D H D$ and violent aggression: What can we learn from epidemiological and genetic studies? Int J Law Psychiatry 2009;32:235-243.

23. Rydén E, Thase ME, Stråht D, Aberg-Wistedt A, Bejerot S, Landén M. A history of childhood attention-deficit hyperactivity disorder (ADHD) impacts clinical outcome in adult bipolar patients regardless of current ADHD. Acta Psychiatr Scand 2009;120:239-246.

24. State RC, Frye MA, Altshuler LL, Strober M, DeAntonio $\mathrm{M}$, Hwang $\mathrm{S}$, et al. Chart review of the impact of attention-deficit/hyperactivity disorder comorbidity on response to lithium or divalproex sodium in adolescent mania. J Clin Psychiatry 2004;65:1057-1063.

25. Rohde P, Clarke GN, Lewinsohn PM, Seeley JR, Kaufman NK. Impact of comorbidity on a cognitive-behavioral group treatment for adolescent depression. J Am Acad Child Adolesc Psychiatry 2001;40:795-802.

26. Biederman J, Ball SW, Monuteaux MC, Mick E, Spencer $\mathrm{TJ}, \mathrm{McCreary} \mathrm{M}$, et al. New insights into the comorbidity between ADHD and major depression in adolescent and young adult females. J Am Acad Child Adolesc Psychiatry
2008;47:426-434.

27. Kim H, Lim SW, Kim S, Kim JW, Chang YH, Carroll BJ, et al. Monoamine transporter gene polymorphisms and antidepressant response in Koreans with late-life depression. JAMA 2006;296:1609-1618.

28. Wang SK, Lee YH, Kim JL, Chee IS. No effect on body dissatisfaction of an interaction between 5-HTTLPR genotype and neuroticism in a young adult Korean population. Clin Psychopharmacol Neurosci 2014;12:229-234.

29. Yoshida K, Ito K, Sato K, Takahashi H, Kamata M, Higuchi $\mathrm{H}$, et al. Influence of the serotonin transporter gene-linked polymorphic region on the antidepressant response to fluvoxamine in Japanese depressed patients. Prog Neuropsychopharmacol Biol Psychiatry 2002;26:383-386.

30. Pollock BG, Ferrell RE, Mulsant BH, Mazumdar S, Miller $\mathrm{M}$, Sweet RA, et al. Allelic variation in the serotonin transporter promoter affects onset of paroxetine treatment response in late-life depression. Neuropsychopharmacology 2000;23:587-590.

31. Sakai JT, Young SE, Stallings MC, Timberlake D, Smolen A, Stetler GL, et al. Case-control and within-family tests for an association between conduct disorder and 5HTTLPR. Am $J$ Med Genet B Neuropsychiatr Genet 2006;141B:825-832.

32. Bayle FJ, Leroy S, Gourion D, Millet B, Olié JP, Poirier $\mathrm{MF}$, et al. 5HTTLPR polymorphism in schizophrenic patients: further support for association with violent suicide attempts. Am J Med Genet B Neuropsychiatr Genet 2003;119B:13-17.

33. Tharoor H, Lobos EA, Todd RD, Reiersen AM. Association of dopamine, serotonin, and nicotinic gene polymorphisms with methylphenidate response in ADHD. Am J Med Genet B Neuropsychiatr Genet 2008;147B:527-530.

34. Davidge KM, Atkinson L, Douglas L, Lee V, Shapiro S, Kennedy JL, et al. Association of the serotonin transporter and 5HT1Dbeta receptor genes with extreme, persistent and pervasive aggressive behaviour in children. Psychiatr Genet 2004; 14:143-146.

35. Dunner DL. A review of the diagnostic status of "bipolar II" for the DSM-IV work group on mood disorders. Depression 1993;1:2-10.

36. Judd LL, Akiskal HS, Schettler PJ, Coryell W, Maser J, Rice $\mathrm{JA}$, et al. The comparative clinical phenotype and long term longitudinal episode course of bipolar I and II: a clinical spectrum or distinct disorders? J Affect Disord 2003;73: 19-32.

37. Rihmer Z, Pestality P. Bipolar II disorder and suicidal behavior. Psychiatr Clin North Am 1999;22:667-73, ix-x.

38. Fletcher K, Parker G, Barrett M, Synnott H, McCraw S. Temperament and personality in bipolar II disorder. J Affect Disord 2012;136:304-309. 